\title{
Association of opioid requirement and cancer pain with survival in advanced non-small cell lung cancer
}

\author{
D. Zylla ${ }^{1,2,4}$, M. A. Kuskowski ${ }^{3}$, K. Gupta ${ }^{1}$ and P. Gupta ${ }^{1,2^{*}}$
}

\author{
${ }^{1}$ Division of Hematology/Oncology/Transplantation, Department of Medicine, University of Minnesota, Minneapolis, MN, USA \\ ${ }^{2}$ Hematology/Oncology Section, Department of Medicine and ${ }^{3}$ Geriatric Research and Education Clinical Center, Minneapolis VA Health Care \\ System, Minneapolis, MN, USA \\ ${ }^{4}$ Present address: Park Nicollet Health Services, Oncology Research, St Louis Park, MN, USA \\ *Corresponding author. E-mail: pankaj.gupta@va.gov
}

\section{Editor's key points}

- Clinical and laboratory evidence suggest that pain and opioid use are associated with survival in cancer.

- A retrospective analysis of pain and opioid use was conducted in 209 patients with advanced lung cancer.

- More severe pain and greater opioid use were independently associated with shorter overall survival.

- Prospective studies are required to determine if reducing opioid use without sacrificing analgesia can improve outcomes.
Background. Pain is associated with shorter survival in non-small cell lung cancer (NSCLC). Lung cancer cells express opioid receptors. Opioids promote angiogenesis, tumour growth, and metastases, and shorten survival in animal models.

Methods. We examined retrospectively if long-term opioid requirement, independently of chronic pain, is associated with reduced survival in 209 patients with stage IIIB/IV NSCLC. Opioid doses were converted to average oral morphine equivalents (OME). Patients were stratified by proportion of time they reported severe pain, and required $<5$ or $\geq 5 \mathrm{mg} \mathrm{day}^{-1}$ OME. Effects of pain, opioid requirement, and known prognostic variables on overall survival were analysed.

Results. Severe pain before chemotherapy initiation was associated with shorter survival (hazards ratio $1.39,95 \%$ confidence interval, $1.02-1.87, P=0.035$ ). The magnitude of pain and opioid requirement during first 90 days of chemotherapy were predictive of shorter survival: patients with no/mild pain and requiring $<5 \mathrm{mg} \mathrm{day}^{-1}$ OME had 12 months longer median survival compared with those requiring more opioids, experiencing more pain, or both (18 compared with 4.2-7.7 months, $P \leq 0.002$ ). Survival differences (16 compared with 5.5-7.8 months, $P<0.001$ ) were similar when chronic pain and opioid requirement were assessed until death or last follow-up. In multivariable models, opioid requirement and chronic pain remained independent predictors of survival, after adjustment for age, stage, and performance status.

Conclusions. The severity of chronic cancer-related pain or greater opioid requirement is associated with shorter survival in advanced NSCLC, independently of known prognostic factors. While pain adversely influences prognosis, controlling it with opioids does not improve survival. Prospective studies should determine if pain control using equi-analgesic opioid-sparing approaches can improve outcomes.

Keywords: analgesics, opioid; metastasis; morphine; mortality; neoplasm recurrence; pain

Accepted for publication: 15 July 2014
Cancer-related pain is common, negatively impacts quality of life (QOL), and often requires opioid analgesics. Two-thirds of patients with advanced malignancies experience pain, with almost $50 \%$ experiencing moderate-severe pain. ${ }^{1}$ Opioid medications are the mainstay of treatment of severe, chronic cancer pain. ${ }^{2} 3$ Experimental studies and retrospective clinical analyses raise concern that opioids might promote cancer progression and reduce survival. ${ }^{4-16}$

However, pain at diagnosis is itself associated with shorter survival in lung cancer $^{17} 18$ and other malignancies. ${ }^{19-22}$ Pain may induce cancer progression via tumour innervation ${ }^{23}$ and release of tachykinins such as substance $P,{ }^{24}$ endogenous opioid peptides that modulate immune function, ${ }^{25}$ or cyclo-oxygenase-mediated prostaglandin release. ${ }^{26} 27$ Therefore, it is unclear whether reduced survival in patients treated with opioids is due to opioids, pain, or both. Since pain has a direct impact on QOL and perhaps disease outcomes, it is critical to understand the independent contribution of pain and opioids to cancer progression and survival in order to develop strategies to improve cancer outcomes.

Lung cancer is the most common malignancy worldwide, ${ }^{28}$ and ranks third highest for pain prevalence among all malignancies. ${ }^{1}$ Preclinical data on cellular mechanisms and murine models demonstrate that opioids promote lung cancer progression and metastasis and reduce survival. ${ }^{561214}$ Opioids directly activate mitogenic signalling via $\mu$-opioid receptors 
(MOR), and also by co-activating receptor tyrosine kinases including vascular endothelial growth factor receptor-2 and epidermal growth factor receptor in endothelial ${ }^{4}$ and lung

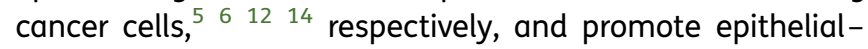
mesenchymal transition. ${ }^{14}$ MOR expression is increased in human lung cancer specimens compared with normal human lungs, ${ }^{29}$ and even higher in lung cancers with metastases to lymph nodes. ${ }^{30}$ Opioids might therefore be associated with lung cancer progression in patients.

In a retrospective study of patients with advanced prostate cancer receiving androgen-deprivation therapy, we found that greater opioid requirement and higher MOR expression in the tumour are independently associated with shorter progression-free survival and overall survival (OS). ${ }^{16}$ Halabi and colleagues ${ }^{22}$ confirmed and extended our findings to patients with advanced prostate cancer receiving first-line chemotherapy, reporting that opioid use is an independent prognostic factor for survival. Some prospective studies suggest that systemic exposure to endogenous or pharmacological opioids promotes cancer progression in patients with astrocytomas, ${ }^{31}$ pancreatic cancer, ${ }^{32}$ and various advanced solid tumours including lung cancer. ${ }^{33}$

However, the above studies did not differentiate between impact of pain and opioid use independently of the other. Previous studies also did not evaluate the effect of chronic (ongoing) pain or long-term quantitative opioid exposure on cancer outcomes. Further, there is marked inter-patient variability in treatment of pain and use of opioids depending upon individual patient pain thresholds and patient and pro-

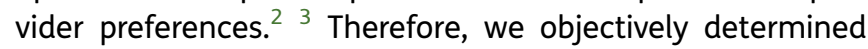
the effect of chronic cancer-related pain and quantitative systemic opioid use, independent of each other, on survival of patients with advanced non-small cell lung cancer (NSCLC).

\section{Methods}

\section{Patients}

We retrospectively studied 209 patients diagnosed with stage IIIB or IV NSCLC from 2003 to 2010 at the Minneapolis Veterans Affairs Health Care System (MVAHCS) treated with palliative chemotherapy to determine whether chronic pain, opioid requirement, or both are associated with survival. Patient characteristics, clinical, and pharmacy data were obtained from patient records, the tumour registry, and VA Data Support Services. The study was approved by the institutional Human Subjects Committee.

\section{Opioid requirement}

All oral and transdermal outpatient opioid prescriptions dispensed from any VA in the USA from 2002 to 2012 were collected to determine the total opioid quantity dispensed per prescription. All opioids were converted to oral morphine equivalents (OME) using an equi-analgesic conversion table. ${ }^{16}$ Average daily opioid requirement was calculated for three distinct treatment intervals: (i) 90 days before chemotherapy initiation, (ii) 90 days after chemotherapy initiation, and (iii) chemotherapy initiation to death or last follow-up.

\section{Pain levels}

All pain values recorded from inpatient and outpatient clinical encounters were collected. Pain levels were analysed for the same three treatment intervals used for opioids. Pain severity was categorized in accordance with the Brief Pain Inventory: low $(0-3)$, moderate $(4-6)$, and severe $(7-10) .{ }^{34}$ For analysis of pain during the 90 days before chemotherapy, we used the patient's maximum reported pain level to maintain consistency and comparability with previous studies which assessed pain before treatment initiation. ${ }^{17} 21$

\section{Pain-opioid groups}

For treatment intervals after chemotherapy initiation, both pain and opioid requirement were separated into high and low groups, to better assess for interactions. The categorization of pain levels, opioid requirement, and patient groupings are shown and explained in Table 1. Briefly, pain was stratified by the proportions of time a patient reported severe or moderate-severe pain. Patients requiring $\geq 5 \mathrm{mg}$ day $^{-1}$ OME were considered to have high opioid use. We previously found that this cut-off (5 mg day ${ }^{-1}$ OME) distinguished patients who used either short courses of opioids intermittently or required opioids only occasionally from patients who required ongoing scheduled opioids. ${ }^{16}$ Four subgroups were created based on the severity of pain and quantitative opioid requirement (Table 1), reflecting clinical scenarios observed in clinical

Table 1 Categorization of pain level and opioid requirement. Patients were stratified into low pain (LP) or high pain (HP) groups, based on the proportion of time they reported severe, or moderate-severe, pain. Categorization of patients into low opioid (LO) or high opioid (HO) groups was based on an opioid requirement cut-off of $5 \mathrm{mg} \mathrm{day}^{-1}$ OME. Four subgroups were created based on pain level and opioid requirement: (i) low pain/low opioid (LPLO: reference group against which the other three groups were compared), (ii) high pain/low opioid (HPLO), (iii) low pain/high opioid (LPHO), and (iv) high pain/high opioid (HPHO). Analyses were performed separately using the severe pain or moderate-severe pain categorizations

\begin{tabular}{|c|c|c|}
\hline & $\begin{array}{l}\text { Low pain (LP) } \\
\text { group }\end{array}$ & $\begin{array}{l}\text { High pain (HP) } \\
\text { group }\end{array}$ \\
\hline Severe pain $(7-10)$ & $\begin{array}{l}<10 \% \text { of all } \\
\text { recordings }\end{array}$ & $\begin{array}{l}\geq 10 \% \text { of all } \\
\text { recordings }\end{array}$ \\
\hline \multirow[t]{2}{*}{$\begin{array}{l}\text { Moderate-severe pain } \\
(4-10)\end{array}$} & $\begin{array}{l}<25 \% \text { of all } \\
\text { recordings }\end{array}$ & $\begin{array}{l}\geq 25 \% \text { of all } \\
\text { recordings }\end{array}$ \\
\hline & $\begin{array}{l}\text { Low opioid (LO) } \\
\text { group }\end{array}$ & $\begin{array}{l}\text { High opioid } \\
\text { (HO) group }\end{array}$ \\
\hline $\begin{array}{l}\text { Average opioid } \\
\text { requirement } \\
\text { (mg day }{ }^{-1} \text { OME) }\end{array}$ & $<5$ & $\geq 5$ \\
\hline Pain & $\begin{array}{l}\text { Opioid requirement } \\
\text { Low }\end{array}$ & High \\
\hline Low & LPLO & LPHO \\
\hline High & HPLO & $\mathrm{HPHO}$ \\
\hline
\end{tabular}


practice: ${ }^{2} 3$ (i) low pain/low opioid (LPLO), (ii) low pain/high opioid (LPHO), (iii) high pain/low opioid (HPLO), and (iv) high pain/high opioid (HPHO). The LPLO (reference) group included patients experiencing minimal pain and requiring no or minimal opioids. The LPHO group included patients with good pain control with high opioid utilization; the HPLO group comprised patients experiencing higher levels of pain but no or minimal opioid utilization (perhaps due to patient preference or intolerability to opioids, or prescribing practices, a wellrecognized phenomenon). ${ }^{2}{ }^{3}$ The HPHO group included patients experiencing higher levels of pain, despite higher opioid use. This grouping thus aimed to separate patients with chronic severe pain alone (HPLO) from those with higher opioid exposure alone (LPHO) from the reference group with neither of these factors (LPLO).

\section{Statistical analysis}

The Cox proportional hazards regression models were used to compare the subgroups for OS. Effects of individual factors on OS were evaluated using the Kaplan-Meier analyses. For the multivariable Cox models, OS was analysed after adjusting for known prognostic factors at the time of diagnosis (age, performance status, and stage of disease). Indicator variable coding was used to compare pain-opioid subgroups (LPLO, HPLO, LPHO, HPHO), with the LPLO group as the reference group.

\section{Results}

\section{Patient characteristics}

The majority of patients were male (98\%), had stage IV disease (71\%), and had good performance status (75\% had ECOG PS of $0-1$ ) (Table 2). Nearly half had experienced severe pain (i.e. at least one pain recording $\geq 7$ ) during 90 days preceding chemotherapy, with a similar proportion receiving opioids before chemotherapy. These percentages show the population to be relatively high functioning with advanced disease, yet balanced with regard to baseline pain and opioid requirement. The predominantly male VA population precludes generalization of our results to women.

\section{Association of pain level and opioid requirement with survival}

We examined in univariable models whether pain level or opioid requirement at different time periods during the course of the disease were associated with survival (Table 3). Chronic severe pain, moderate-severe pain, or high opioid requirement in the first 90 days of chemotherapy, or during the entire treatment period (chemotherapy initiation to death or last follow-up), was significantly associated with shorter OS. However, while patients experiencing a maximum pain level $\geq 7$ before initiation of chemotherapy had shorter survival, greater opioid requirement before chemotherapy initiation was not associated with OS.

Table 2 Baseline patient characteristics

\begin{tabular}{|c|c|c|}
\hline & All patients $(n=209)$ & \\
\hline Median age at diagnosis, yr (range) & & $63(45-83)$ \\
\hline Sex (male, female) $[n(\%)]$ & & $205,4(98,2 \%)$ \\
\hline Stage IIIB, IV [n (\%)] & & $61,148(29,71 \%)$ \\
\hline ECOG scale performance status [ $n(\%)]$ & $\begin{array}{l}0 \\
1 \\
2 \\
3 \\
4\end{array}$ & $\begin{aligned} & 42(20) \\
& 115(55) \\
& 46(22) \\
& 6(3) \\
& 0(0)\end{aligned}$ \\
\hline Histological subtype $[n(\%)]$ & $\begin{array}{l}\text { Adenocarcinoma } \\
\text { Squamous cell carcinoma } \\
\text { Non-small cell lung cancer, NOS } \\
\text { Large cell carcinoma } \\
\text { Others }\end{array}$ & $\begin{array}{l}81(39) \\
49(23) \\
65(31) \\
7(3) \\
7(3)\end{array}$ \\
\hline Highest pain level at diagnosis (before initiation of chemotherapy) [n (\%)] & $\begin{array}{l}\text { None (level 0) } \\
\text { Mild (level 1-3) } \\
\text { Moderate (level 4-6) } \\
\text { Severe (level 7-10) }\end{array}$ & $\begin{array}{l}42(20) \\
26(12) \\
46(22) \\
95(46)\end{array}$ \\
\hline Pain level of the entire cohort at diagnosis (before initiation of chemotherapy) & Median, level 6 & \\
\hline Opioid requirement at diagnosis, OME day ${ }^{-1}$ (before initiation of chemotherapy) [n (\%)] & $\begin{array}{l}\text { None (0 mg day }{ }^{-1} \text { OME) } \\
\left.\text { Minimal ( } 0.01-4.99 \mathrm{mg}^{-1 a y}{ }^{-1} \mathrm{OME}\right) \\
\text { Moderate (5-29.99 mg day }{ }^{-1} \text { OME) } \\
\text { High ( } \geq 30 \mathrm{mg} \mathrm{day}^{-1} \text { OME) }\end{array}$ & $\begin{array}{l}77(37) \\
44(21) \\
48(23) \\
40(19)\end{array}$ \\
\hline Opioid requirement of entire cohort at diagnosis (before initiation of chemotherapy) & $\begin{array}{l}\text { Average, } 28.7 \mathrm{mg} \mathrm{day}^{-1} \mathrm{OME} \\
\text { Median, } 2.6 \mathrm{mg} \mathrm{day}^{-1} \mathrm{OME}\end{array}$ & \\
\hline
\end{tabular}


Table 3 Association of chronic pain and opioid requirements with overall survival. *Maximum pain before chemotherapy: high-had at least one pain level $\geq 7$ in the 90 days before chemotherapy initiation; low-had all pain levels $<7$ in the 90 days before chemotherapy initiation. ${ }^{\dagger} O p$ ioid requirements during various time intervals: high: average opioid utilization of $\geq 5 \mathrm{mg} \mathrm{day}^{-1}$ OME during time interval selected; low: average opioid utilization of $<5 \mathrm{mg}$ day $^{-1} \mathrm{OME}$ during time interval selected. ${ }^{\ddagger}$ Severe pain during various time intervals: high: pain levels $\geq 7$ on $\geq 10 \%$ of recordings during time interval selected; low: pain levels $\geq 7$ on $<10 \%$ of recordings during time interval selected. "Moderate-severe pain during various time intervals: high: pain levels $\geq 4$ on $\geq 25 \%$ of recordings during time interval selected; low: pain levels $\geq 4$ on $<25 \%$ of recordings during time interval selected

\begin{tabular}{lllr}
\hline Predictor interval & Predictor & Hazard ratio for overall survival (95\% CI) & P-value \\
\hline 90 days before chemotherapy initiation & Maximum pain level (high vs low) & $1.39(1.02-1.87)$ & 0.035 \\
& Opioid requirement (high vs low) & $0.92(0.68-1.25)$ & 0.606 \\
First 90 days after chemotherapy initiation & Severe pain (high vs low) & $1.43(1.02-2.00)$ & 0.040 \\
& Moderate-severe pain (high vs low) & $1.61(1.17-2.21)$ & 0.003 \\
& Opioid requirement (high vs low) & $1.45(1.07-1.96)$ & 0.016 \\
Chemotherapy initiation to last status date & Severe pain (high vs low) & $1.35(0.99-1.86)$ & 0.061 \\
& Moderate-severe pain (high vs low) & $1.53(1.11-2.11)$ & 0.009 \\
& Opioid requirement (high vs low) & $1.83(1.32-2.55)$ & $<0.001$ \\
\hline
\end{tabular}

\section{Individual effects of pain level and opioid requirement on survival}

We next attempted to differentiate individual associations of pain and opioids with survival, using pain/opioid groupings [LPLO (reference group), HPLO, LPHO, and HPHO] as described in the Methods section. Analyses were performed for two time intervals in the clinical course (first 90 days of chemotherapy, and chemotherapy initiation to death or last follow-up) and for two pain stratifications (severe pain and moderatesevere pain). The probabilities of survival in each of these groups were estimated using the Kaplan-Meier analyses (Fig. 1).

\section{Association of pain and opioid requirement in the first 90 days after chemotherapy initiation with survival}

Survival of patients in the LPLO (reference) group was significantly longer compared with the HPLO, LPHO, and HPHO groups (median survival 17.9 compared with $5.7,6.5$, and 6.1 months, respectively, log-rank $P$-value $=0.002$ ) stratified on the presence of severe pain (Fig. 1A). Similarly, markedly different survivals were observed between the LPLO group and the other three groups when patients were stratified on the presence of moderate-severe pain (17.9 compared with 5.7, 7.7, and 4.2 months, respectively, log-rank $P$-value $=0.001$; Fig. 1B). These findings suggest that higher levels of pain, greater opioid requirement early in the treatment period, or both are predictive of shorter survival in patients with advanced NSCLC.

\section{Association of pain and opioid requirement during the entire clinical course with survival}

Remarkably similar differences in survival were observed between the reference LPLO group and the other three groups when pain level and opioid requirement were assessed from chemotherapy initiation to death or last follow-up. The median survival in the LPLO group was significantly longer compared with the HPLO, LPHO, and HPHO groups (16.0 compared with $5.5,6.5$, and 7.8 months, respectively, log-rank
$P$-value $<0.001)$ stratified by severe pain (Fig. 1c). Again, similar survival differences were seen using the moderatesevere pain stratification for this treatment interval $(16.4 \mathrm{com}$ pared with 6.4, 7.1, and 7.7 months, respectively, log-rank $P$-value $\leq 0.001$ ) (Fig. 1D). These findings indicate that the presence of chronic pain or high opioid requirement is associated with markedly shorter survival in patients with advanced NSCLC. Patients experiencing little to no pain and also consuming $<5 \mathrm{mg} \mathrm{OME} \mathrm{day}^{-1}$ had considerably longer survival.

\section{Multivariable analyses of pain, opioids, and known prognostic factors}

Finally, we evaluated if chronic pain level, opioid requirement, or both are associated with differences in survival when clinical prognostic variables (age, performance status, and stage of disease) are included in the multivariable Cox regression analyses (Table 4). Longer survival of patients in the LPLO reference group remained significant for both pain classifications (severe pain or moderate-severe pain) and both treatment intervals (first 90 days after chemotherapy initiation or chemotherapy initiation to death or last follow-up). In all these analyses, age, performance status, and stage also remained significantly associated with survival, confirming the validity of the data set and outcomes. Of particular relevance, these results indicate that chronic pain, higher opioid requirement in the first 3 months of treatment, or both are individually and independently predictive of shorter survival in patients with advanced NSCLC.

\section{Discussion}

QOL and survival are influenced by pain and its treatment in cancer patients. However, it is not known if pain and analgesics influence these outcomes independent of one another or if their effects are interdependent. We found in this retrospective study that the presence of either chronic severe pain or greater quantitative opioid requirement was associated with markedly shorter survival in patients with advanced NSCLC, independent of known clinical prognostic factors. 


\section{A: Opioid requirement and severe pain during first 90 days of chemotherapy}

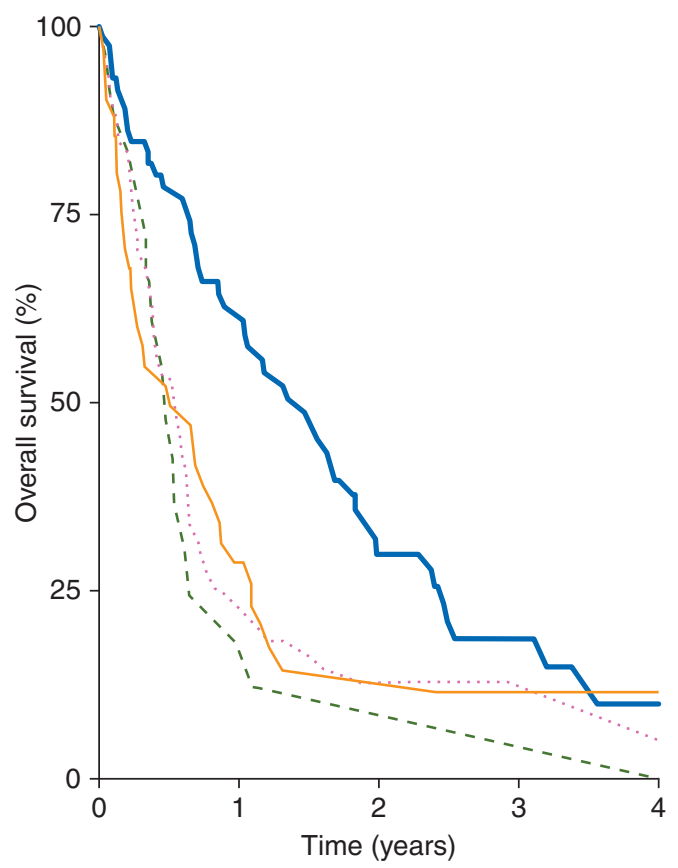

C: Opioid requirement and severe pain during the entire clinical course

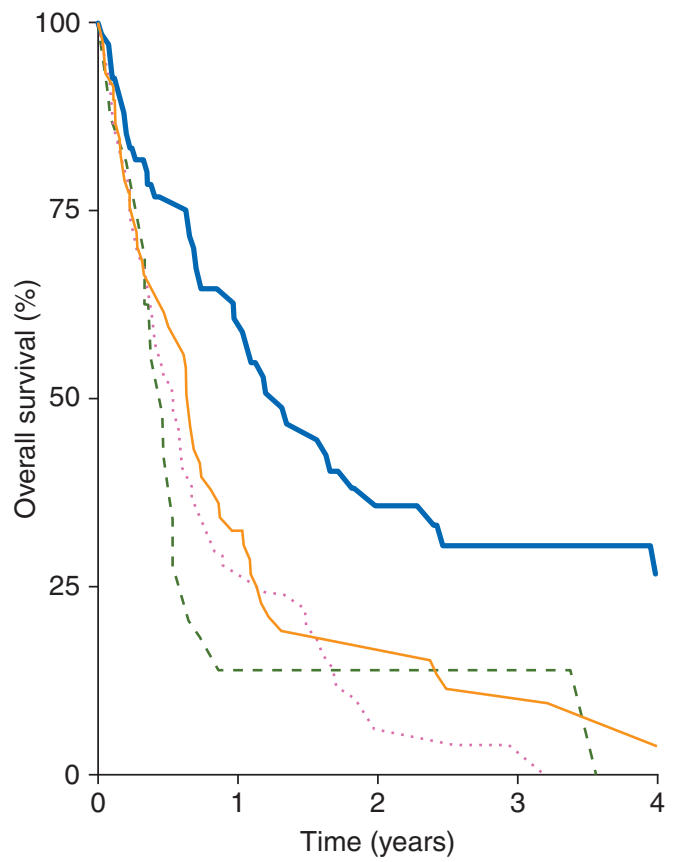

B: Opioid requirement and moderate-severe pain during first 90 days of chemotherapy

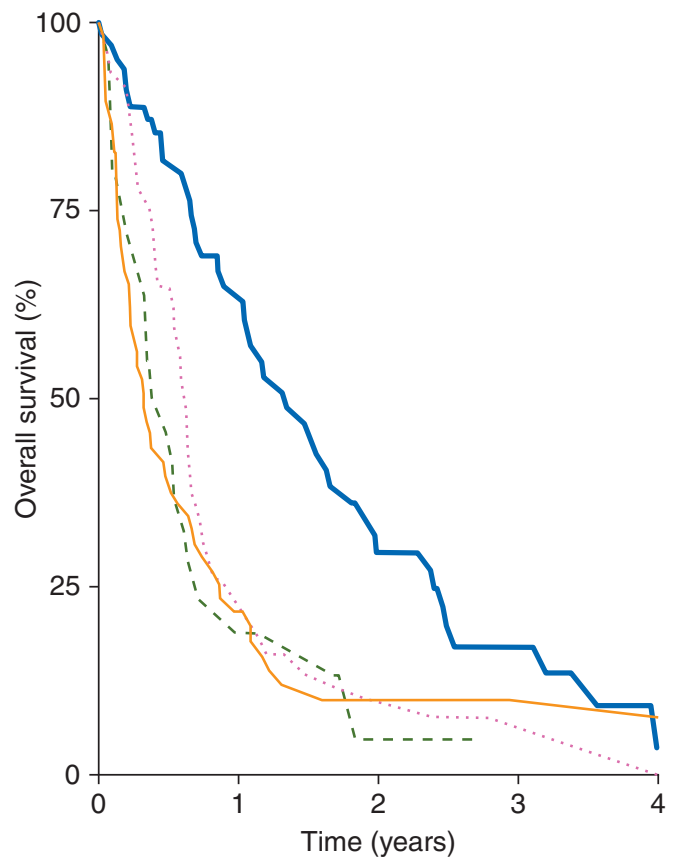

D: Opioid requirement and moderate-severe pain during the entire clinical course

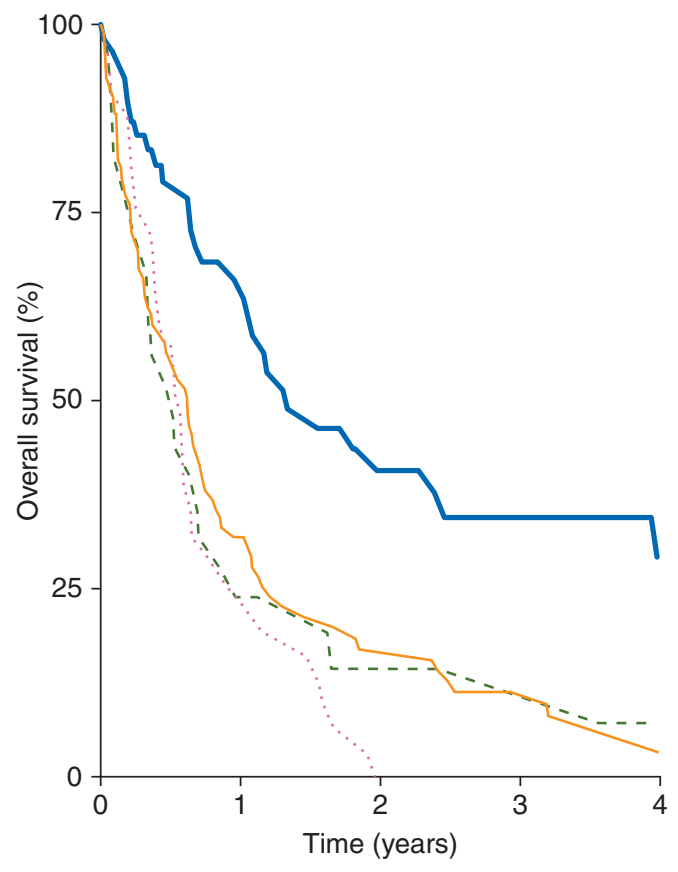

Low pain, high opioids High pain, high opioids

Fig 1 Overall survival of patients experiencing different levels of chronic pain and requiring varying amounts of opioids (defined as described in the Methods section and Table 1) was estimated using the Kaplan-Meier method. The presence of higher levels of pain, greater opioid requirement, or both was strongly associated with shorter survival. Statistical analysis is provided in the Results section. The panels show the overall survival of patients stratified by opioid requirement and $(A)$ severe pain during the first 90 days of chemotherapy, (B) moderate-severe pain during the first 90 days of chemotherapy, (c) severe pain during the entire clinical course (from initiation of chemotherapy to death or last follow-up), and (D) moderate-severe pain during the entire clinical course. 
Table 4 Independent associations of chronic pain and opioid requirements with overall survival in multivariable models including known prognostic factors. *Severe pain: high pain (HP)—had pain levels $\geq 7$ on $\geq 10 \%$ of recordings during time interval selected; low pain (LP)—had pain levels $\geq 7$ on $<10 \%$ of recordings during time interval selected. ${ }^{\dagger}$ Moderate-severe pain: high pain (HP)-had pain levels $\geq 4$ on $\geq 25 \%$ of recordings during time interval selected; low pain (LP) - had pain levels $\geq 4$ on $<25 \%$ of recordings during time interval selected. ${ }^{\ddagger}$ Four subgroups were created based on pain levels and opioid requirements, as detailed in Table 1: (i) low pain/low opioid (LPLO: reference group against which the other three groups were compared; hazard ratio=1.00), (ii) high pain/low opioid (HPLO), (iii) low pain/high opioid (LPHO), and (iv) high pain/high opioid (HPHO)

\begin{tabular}{|c|c|c|c|c|c|c|c|c|}
\hline \multirow[b]{3}{*}{ Predictor } & \multicolumn{4}{|c|}{ First 90 days after chemotherapy initiation } & \multicolumn{4}{|c|}{ Chemotherapy initiation to last status date } \\
\hline & \multicolumn{2}{|l|}{ Severe pain* } & \multicolumn{2}{|c|}{ Moderate-severe pain $^{\dagger}$} & \multicolumn{2}{|l|}{ Severe pain* } & \multicolumn{2}{|c|}{ Moderate-severe pain ${ }^{\dagger}$} \\
\hline & $\begin{array}{l}\text { Hazard ratio } \\
(95 \% \mathrm{CI})\end{array}$ & P-value & $\begin{array}{l}\text { Hazard ratio } \\
(95 \% \mathrm{CI})\end{array}$ & P-value & $\begin{array}{l}\text { Hazard ratio } \\
(95 \% \mathrm{CI})\end{array}$ & P-value & $\begin{array}{l}\text { Hazard ratio } \\
(95 \% \mathrm{CI})\end{array}$ & $P$-value \\
\hline $\mathrm{HPLO}^{\ddagger}$ & $2.62(1.45-4.73)$ & 0.001 & $2.11(1.24-3.61)$ & 0.006 & $3.21(1.69-6.09)$ & $<0.001$ & $2.82(1.61-4.96)$ & $<0.001$ \\
\hline $\mathrm{LPHO}^{\ddagger}$ & $1.91(1.28-2.85)$ & 0.002 & $1.80(1.17-2.79)$ & 0.008 & $2.07(1.34-3.20)$ & 0.001 & $2.15(1.25-3.71)$ & 0.006 \\
\hline $\mathrm{HPHO}^{\ddagger}$ & $2.01(1.26-3.21)$ & 0.003 & $2.12(1.37-3.29)$ & 0.001 & $2.28(1.45-3.58)$ & $<0.001$ & $2.66(1.69-4.21)$ & $<0.001$ \\
\hline Age & $1.03(1.01-1.05)$ & 0.002 & $1.03(1.01-1.04)$ & 0.005 & $1.03(1.01-1.05)$ & 0.001 & $1.04(1.02-1.06)$ & $<0.001$ \\
\hline $\begin{array}{l}\text { Performance } \\
\text { status (ECOG) }\end{array}$ & $1.28(1.04-1.58)$ & 0.022 & $1.28(1.03-1.59)$ & 0.026 & $1.28(1.05-1.58)$ & 0.017 & $1.28(1.03-1.58)$ & 0.025 \\
\hline Stage (IIIB vs IV) & $1.52(1.25-1.86)$ & $<0.001$ & $1.52(1.25-1.86)$ & $<0.001$ & $1.46(1.19-1.78)$ & $<0.001$ & $1.46(1.20-1.78)$ & $<0.001$ \\
\hline
\end{tabular}

The independent impact of chronic pain on clinical outcomes can be difficult to discern because it is often incorporated into QOL assessment instruments that generate global QOL scores. To specifically examine influence of chronic pain by itself on survival, we took advantage of the VA's electronic databases that document every pain level reported by inpatients and outpatients over the entire course of disease; these databases provide comprehensive assessments since patients in the VA system are rarely lost to follow-up or receive treatment elsewhere. To minimize the disproportionate impact of single pain levels (which can fluctuate widely), we categorized patients by the severity of chronic pain by calculating the proportion of times a patient reported pain above certain levels on a 0-10 scale over a longer period of time. This approach also allowed us to incorporate into our analyses all pain levels from any clinical encounter patients had in the VA system.

Prior reports have separately shown that pain and opioid requirement are prognostic factors for OS in various malignancies, ${ }^{16} 1722$ but none of these studies simultaneously examined the individual or combined effects of both these interrelated factors. Segregating severity of pain from opioid utilization poses a major challenge in such analyses. We were able to identify subgroups of patients experiencing higher levels of pain but not exposed to much opioid (HPLO group), those experiencing little or no chronic pain but exposed to larger quantities of opioids (LPHO group), and those experiencing greater pain and exposed to higher amounts of opioids (HPHO group). ${ }^{2}{ }^{3}$ Comparing these groups with a reference group of patients without much pain or opioid exposure (LPLO group) allowed exploration of the potential impact of pain alone (HPLO group), opioids alone (LPHO group), or both factors on clinical outcomes. This strategy was able to identify highly significant and independent associations of pain and opioid requirement on overall survival and might provide a useful method to evaluate the influence of these interrelated factors in other malignancies.
These clinical data complement earlier studies from our laboratory showing that chronic opioid administration leads to increased cancer progression and metastasis and reduced survival in mice with breast cancer. ${ }^{715}$ Hyperalgesia continued to increase in both control and morphine-treated mice over time, but co-treatment with morphine and celecoxib (a COX-2 inhibitor) reduced hyperalgesia and also cancer progression and metastasis and improved survival, suggesting that pain is associated with cancer progression and survival. ${ }^{7}$ Opioid-induced hyperalgesia could amplify existing pain, and might be an additional factor contributing to inferior outcomes in cancer. Thus, the present clinical observations together with earlier animal studies demonstrate that pain might critically influence survival, independent of opioid use. Of course, our retrospective study demonstrating this association cannot prove causation, which must await further prospective studies.

Recent studies in humans support the hypothesis generated by preclinical studies that stimulation of opioid receptor signalling promotes cancer progression, which could influence survival. Madar and colleagues ${ }^{29}$ showed using positron emission tomography that human lung cancers express higher levels of opioid receptors in vivo compared with adjacent normal lung tissue; binding of ligands (and thus likely also pharmacological and endogenous opioids) was effectively blocked by opioid antagonists in tumour tissue in vivo. These findings suggest that it might be possible to block potential adverse effects of opioid receptor signalling in cancers. The need to examine the possible benefit of such strategies is underscored by our observation that both increased MOR expression and greater opioid requirement are independently associated with shorter progression-free and overall survival in prostate cancer patients. ${ }^{16}$

Pain at diagnosis of metastatic NSCLC has been cited as a prognostic factor. In a comprehensive literature search of pain in patients with stage IIIB or IV NSCLC, we found that pain at diagnosis was significantly associated with shorter survival on univariable analyses in $\sim 80 \%$ of studies 
(unpublished results). Pain remained significant when clinical variables including age, gender, performance status, and stage of disease were included in multivariable analyses in some studies. ${ }^{17} 18$ However, none of these studies assessed the impact of chronic (long-term) pain, opioid requirement, or MOR expression on outcomes. Consistent with these reports, we observed that level of pain at diagnosis was significantly associated with survival. However, given the subjective and highly variable nature of pain, determination of a single pain level at diagnosis cannot reliably reflect the intensity (or influence) of long-term chronic pain experienced by patients with advanced malignancies.

Poor survival of patients in the LPHO group could be related to the adverse effects of opioids. Alternatively, it is possible that pathways activated by pain ${ }^{23-27}$ continue to exert detrimental effects in advanced malignancies even after the perception of pain is relieved by opioid analgesics. Further investigation is required to distinguish between these possibilities.

Our study analysed the association of chronic pain (from diagnosis till death) and quantitative, long-term opioid requirement with survival in patients with advanced cancer. Several retrospective ${ }^{35-39}$ and one prospective ${ }^{40}$ studies have examined the association of recurrence or survival with anaesthetic technique, short-term perioperative opioid administration in patients operated for early stage malignancies, or both. However, the pharmacological effects of opioids, immune function, opioid receptor expression, and activity are likely different in the two settings.

Measuring predictors (pain level and opioid requirement) concurrently with outcome (survival) up till the time of death can introduce statistical bias. We therefore also analysed the association of predictors (pain and opioids) restricted to the first 90 days of chemotherapy (during which few patients died), with subsequent survival. Restricting analysis to the first 90 days after chemotherapy initiation also helped reduce the disproportionate impact of increasing pain and opioid requirement as patients approached the end of life (hospice care). In addition to avoiding statistical bias, our findings with this approach indicate that severity of pain and quantitative opioid requirement early in the clinical course of advanced NSCLC are strongly and independently predictive of survival. Demonstrating significant and remarkably comparable associations with both pain predictors (severe pain or moderatesevere pain) and both analysis intervals further strengthens the validity of our findings.

Limitations of this study include the following: (i) it is retrospective, (ii) opioid prescriptions dispensed were used as a measure of actual opioid consumption, (iii) the confounding effect of tumour location and extent on pain levels, opioid requirements and outcomes could not be entirely excluded, (iv) it included various histologies that are grouped under NSCLC, (v) it did not specifically distinguish cancer-related pain from pain related to chemotherapy or radiation, and (vi) nonsteroidal anti-inflammatory drug use during chemotherapy, although very infrequent, was not incorporated in the analysis.

In conclusion, we report that patients with advanced NSCLC experiencing more severe chronic cancer-related pain or having greater long-term opioid requirement experience shorter survival, independently of the influence of known prognostic factors. Importantly, while pain is an independent prognostic factor, controlling it with opioid medications was not associated with improve outcomes. Prospective investigations are warranted to determine if managing pain with opioid-sparing approaches improves survival in patients with advanced malignancies. Until results of such studies are available, clinical practice aimed at relieving cancer pain should not be changed.

\section{Authors' contributions}

D.Z.: study design, data acquisition, analysis, and interpretation; M.A.K.: statistical analysis and interpretation; K.G.: development of concept, interpretation of results; P.G.: development of concept and study design, data interpretation, overall responsibility for conduct of study. All authors contributed towards writing the manuscript.

\section{Acknowledgements}

We thank Christa Kramer, Valerie Grant, Kim McMonigal, and Patricia Albrecht for patient identification and data extraction, and Dr Robert A. Kratzke (University of Minnesota) for critical review of the manuscript.

\section{Declaration of interest}

None declared.

\section{Funding}

Veterans Health Administration (P.G., D.Z.); University of Minnesota Foundation and National Institutes of Health (NIH) grant R01HL68802 (K.G.); NIH T32 HL007062-34 (D.Z.).

\section{References}

1 van den Beuken-van Everdingen $M H$, de Rijke JM, Kessels AG, Schouten HC, van Kleef M, Patijn J. Prevalence of pain in patients with cancer: a systematic review of the past 40 years. Ann Oncol 2007; 18: 1437-49

2 Apolone G, Corli O, Caraceni A, et al. Pattern and quality of care of cancer pain management. Results from the Cancer Pain Outcome Research Study Group. Br J Cancer 2009; 100: 1566-74

3 Barbera LC, Seow H, Husain A, et al. How often are opioids prescribed for cancer patients reporting pain? A population-based analysis. J Clin Oncol 2011; 29: abstr 6084

4 Gupta K, Kshirsagar S, Chang L, et al. Morphine stimulates angiogenesis by activating proangiogenic and survival-promoting signaling and promotes breast tumor growth. Cancer Res 2002; 62: 4491-8

5 Fujioka N, Nguyen J, Chen C, et al. Morphine-induced epidermal growth factor pathway activation in non-small cell lung cancer. Anesth Analg 2011; 113: 1353-64

6 Mathew B, Lennon FE, Siegler J, et al. The novel role of the mu opioid receptor in lung cancer progression: a laboratory investigation. Anesth Analg 2011; 112: 558-67

7 Farooqui M, Li Y, Rogers T, et al. COX-2 inhibitor celecoxib prevents chronic morphine-induced promotion of angiogenesis, tumour 
growth, metastasis and mortality, without compromising analgesia. Br J Cancer 2007; 97: 1523-31

8 Singleton PA, Lingen MW, Fekete MJ, Garcia JG, Moss J. Methylnaltrexone inhibits opiate and VEGF-induced angiogenesis: role of receptor transactivation. Microvasc Res 2006; 72: 3-11

9 Farooqui M, Geng ZH, Stephenson EJ, Zaveri N, Yee D, Gupta K. Naloxone acts as an antagonist of estrogen receptor activity in MCF-7 cells. Mol Cancer Ther 2006; 5: 611-20

10 Zagon IS, McLaughlin PJ. Naltrexone modulates tumor response in mice with neuroblastoma. Science 1983; 221: 671-3

11 Chen C, Farooqui M, Gupta K. Morphine stimulates vascular endothelial growth factor-like signaling in mouse retinal endothelial cells. Curr Neurovasc Res 2006; 3: 171-80

12 Lennon FE, Mirzapoiazova T, Mambetsariev B, Salgia R, Moss J, Singleton PA. Overexpression of the mu-opioid receptor in human non-small cell lung cancer promotes Akt and mTOR activation, tumor growth, and metastasis. Anesthesiology 2012; 116: 857-67

13 Singleton PA, Moreno-Vinasco L, Sammani S, Wanderling SL, Moss J, Garcia JG. Attenuation of vascular permeability by methylnaltrexone: role of mOP-R and S1P3 transactivation. Am J Respir Cell Mol Biol 2007; 37: 222 - 31

14 Lennon FE, Mirzapoiazova T, Mambetsariev B, et al. The mu opioid receptor promotes opioid and growth factor-induced proliferation, migration and epithelial mesenchymal transition (EMT) in human lung cancer. PloS One 2014; 9: e91577

15 Nguyen J, Luk K, Vang D, et al. Morphine stimulates cancer progression and mast cell activation and impairs survival in transgenic mice with breast cancer. Br J Anaesth 2014; 113 (Suppl. 1): i4-13

16 Zylla D, Gourley BL, Vang D, et al. Opioid requirement, opioid receptor expression, and clinical outcomes in patients with advanced prostate cancer. Cancer 2013; 119: 4103-10

17 Herndon JE II, Fleishman S, Kornblith AB, Kosty M, Green MR, Holland J. Is quality of life predictive of the survival of patients with advanced nonsmall cell lung carcinoma? Cancer 1999; 85: 333-40

18 Efficace F, Bottomley A, Smit EF, et al. Is a patient's self-reported health-related quality of life a prognostic factor for survival in non-small-cell lung cancer patients? A multivariate analysis of prognostic factors of EORTC study 08975. Ann Oncol 2006; 17: 1698-704

19 Armstrong AJ, Garrett-Mayer E, Ou Yang YC, et al. Prostate-specific antigen and pain surrogacy analysis in metastatic hormonerefractory prostate cancer. J Clin Oncol 2007; 25: 3965-70

20 Halabi S, Vogelzang NJ, Kornblith AB, et al. Pain predicts overall survival in men with metastatic castration-refractory prostate cancer. J Clin Oncol 2008; 26: 2544-9

21 Quinten C, Coens C, Mauer M, et al. Baseline quality of life as a prognostic indicator of survival: a meta-analysis of individual patient data from EORTC clinical trials. Lancet Oncol 2009; 10: 865-71

22 Halabi S, Lin CY, Kelly WK, et al. Updated prognostic model for predicting overall survival in first-line chemotherapy for patients with metastatic castration-resistant prostate cancer. J Clin Oncol 2014; 32: $671-7$

23 Magnon C, Hall SJ, Lin J, et al. Autonomic nerve development contributes to prostate cancer progression. Science 2013; 341: 1236361

24 Garcia-Recio S, Fuster G, Fernandez-Nogueira P, et al. Substance P autocrine signaling contributes to persistent HER2 activation that drives malignant progression and drug resistance in breast cancer. Cancer Res 2013; 73: 6424-34

25 Boehncke S, Hardt K, Schadendorf D, Henschler R, Boehncke WH, Duthey $\mathrm{B}$. Endogenous mu-opioid peptides modulate immune response towards malignant melanoma. Exp Dermatol 2011; 20: 24-8

26 Iniguez MA, Rodriguez A, Volpert OV, Fresno M, Redondo JM. Cyclooxygenase-2: a therapeutic target in angiogenesis. Trends Mol Med 2003; 9: 73-8

27 Mantyh PW. Cancer pain and its impact on diagnosis, survival and quality of life. Nat Rev Neurosci 2006; 7: 797-809

28 WHO. Globocan 2012: Estimated Cancer Incidence, Mortality and Prevalence Worldwide in 2012. 2012. Available from http:/l globocan.iarc.fr/Pages/fact_sheets_cancer.aspx (accessed February 2014)

29 Madar I, Bencherif B, Lever J, et al. Imaging delta- and mu-opioid receptors by PET in lung carcinoma patients. J Nucl Med 2007; 48: 207-13

30 Singleton PA, Mirzapoiazova T, Hasina R, Salgia R, Moss J. Increased mu-opioid receptor expression in metastatic lung cancer. $\mathrm{Br} J$ Anaesth 2014; 113 (Suppl. 1): i103-8

31 Lissoni P, Meregalli S, Fossati V, et al. Radioendocrine therapy of brain tumors with the long acting opioid antagonist naltrexone in association with radiotherapy. Tumori 1993; 79: 198-201

32 Lillemoe KD, Cameron JL, Kaufman HS, Yeo CJ, Pitt HA, Sauter PK. Chemical splanchnicectomy in patients with unresectable pancreatic cancer. A prospective randomized trial. Ann Surg 1993; 217: 447-55

33 Smith TJ, Staats PS, Deer T, et al. Randomized clinical trial of an implantable drug delivery system compared with comprehensive medical management for refractory cancer pain: impact on pain, drug-related toxicity, and survival. J Clin Oncol 2002; 20: $4040-9$

34 Cleeland CS, Ryan KM. Pain assessment: global use of the Brief Pain Inventory. Ann Acad Med, Singapore 1994; 23: 129-38

35 Biki B, Mascha E, Moriarty DC, Fitzpatrick JM, Sessler DI, Buggy DJ. Anesthetic technique for radical prostatectomy surgery affects cancer recurrence: a retrospective analysis. Anesthesiology 2008; 109: $180-7$

36 Christopherson R, James KE, Tableman M, Marshall P, Johnson FE. Long-term survival after colon cancer surgery: a variation associated with choice of anesthesia. Anesth Analg 2008; 107: 325-32

37 Exadaktylos AK, Buggy DJ, Moriarty DC, Mascha E, Sessler DI. Can anesthetic technique for primary breast cancer surgery affect recurrence or metastasis? Anesthesiology 2006; 105: 660-4

38 Gottschalk A, Ford JG, Regelin CC, et al. Association between epidural analgesia and cancer recurrence after colorectal cancer surgery. Anesthesiology 2010; 113: 27-34

39 Cata JP, Keerty V, Keerty D, et al. A retrospective analysis of the effect of intraoperative opioid dose on cancer recurrence after non-small cell lung cancer resection. Cancer Med 2014; 3: 900-8

40 Myles PS, Peyton P, Silbert B, Hunt J, Rigg JR, Sessler DI. Perioperative epidural analgesia for major abdominal surgery for cancer and recurrence-free survival: randomised trial. Br Med J 2011; 342: d1491 